\title{
Berberine Exerts a Protective Effect on Gut-Vascular Barrier via the Modulation of the Wnt/Beta-Catenin Signaling Pathway During Sepsis
}

\author{
Yan $\mathrm{He}^{\mathrm{a}}$ Xiaoming Yuan ${ }^{\mathrm{b}} \quad \mathrm{Hao}_{\mathrm{Zuo}}^{\mathrm{b}}$ Ying Sun ${ }^{\mathrm{b}}$ Aiwen Feng \\ aDepartment of Oncology Radiotherapy, Huai'an First Hospital, the Affiliated to Nanjing Medical \\ University, Huai'an, 'Department of Gastrointestinal Surgery, Huai'an First Hospital, the Affiliated to \\ Nanjing Medical University, Huai'an, China
}

\section{Key Words}

Intestinal mucosa - Gut-vascular barrier - Vascular permeability - Polymicrobial sepsis Berberine hydrochloride $\cdot$ Claudin-12 $\cdot$ VE-cadherin $\bullet$ Beta-catenin

\begin{abstract}
Background/Aims: The gut-vascular barrier (GVB) has recently been depicted to dampen the bacterial invasion of the bloodstream. The intestinal mucosa is a tissue rich in small vessels including capillaries. In this study, the protective effect of berberine on GVB in small bowel mucosa was investigated. Methods: The rat cecal ligation and puncture (CLP) sepsis model was employed to evaluate the effect of berberine on serum endotoxin level and intestinal vascular permeability to Evans blue in vivo. The rat intestinal microvascular endothelial cells (RIMECs) treated by lipopolysaccharide (LPS) were used to assess the effect of berberine on endothelial permeability to FITC-labeled dextran, transendothelial electrical resistance (TEER), and tight junction (TJ) and adherens junction (AJ) expression in vitro. Results: After 24-hr CLP operation the serum endotoxin concentration and gut vascular permeability were significantly increased, while berberine markedly reduced endotoxin level and vascular leakage. In vitro, LPS not only dramatically increased endothelial permeability of RIMECs to FITC-dextran, but also decreased TEER and inhibited claudin-12, beta-catenin and VE-cadherin expression. These effects of LPS were antagonized by berberine. In addition, our in vivo and vitro studies also confirmed that the effect of berberine on GVB could be partially abolished by ICG001. Conclusion: Berberine exerted a protective effect on GVB function in sepsis, which was strictly related to the modulation of the $\mathrm{Wnt} /$ beta-catenin signaling pathway.
\end{abstract}




\section{Introduction}

The intestine is continuously exposed to a huge amount of foreign antigens, mostly food proteins and microorganisms more than 100 trillion bacteria, including beneficial species, harmful groups and conditional pathogenic bacteria. Under physiological condition, lipopolysaccharide from gram negative flora is absorbed in minute quantities [1]. However, during severe intestinal pathology with a result of perturbation of the gut-vascular barrier (GVB), a large amount of bacteria and toxins can translocate into the bloodstream and reach the distant organs such as the liver [2].

Resembling to the enterocyte, the vascular endothelium is one of major compositions of intestinal mucosal tissue. It has been reported that subcutaneous challenge of mice with LPS produces a gut microvascular lesions characterized by the damage of endothelial cell, microthrombi in the venules and capillaries of mucosal lamina propria [3]. LPS not only damages gut vascular integrity and increases permeability [4-6], but also reduces tight junction (TJ) and adherens junction (AJ) protein production in vascular endothelial cells $[7,8]$. In the intestine, the vascular permeability is strictly regulated and thus vascular endothelial layer possesses barrier properties. Therefore, the impairment of GVB plays a key role in touching off bacterial and toxin translocation [2].

Berberine, an alkaloid compound extracted from herbs such as Cortex phellodendri and Rhizoma coptidis, possesses an anti-inflammatory property. In a sepsis model, berberine attenuates LPS-induced acute lung injury $[9,10]$ via the inhibition of cytokine release, leukocyte-endothelium adhesion and vascular cell adhesion molecule-1 (VCAM-1) expression [10]. In a diabetes model, berberine protects vascular endothelial cell via the promotion of endogenous nitric oxide release [11]. In vitro, berberine inhibits the secretion of NO, ET-1, TNF $\alpha$, IL-1 $\alpha$, IL-6, IL-8, E-selectin and TXB2 from rat intestinal microvascular endothelial cells (RIMECs) in response to LPS stimulus [12, 13]. In addition, berberine reduces circulating microparticles, inhibits apoptosis of leukocyte-mediated endothelium [14], activates peroxisome proliferator-activated receptor gamma (PPAR $\gamma$ ) and suppresses oxidative stress $[15,16]$, ameliorates vascular permeability and increases tight junction by the upregulation of claudins (e.g., claudin-5) [17]. In the present study we aimed to investigate whether berberine might protect GVB via the modulation of the Wnt/beta-catenin signaling pathway, which can be blocked by inhibitor ICG001 both in vivo and vitro experiments [1821].

\section{Materials and Methods}

\section{CLP model of polymicrobial sepsis}

The male Long-Evans rats (weighing 270 300 gram) were housed at controlled room temperature with free access to food and water under a day/night cycle. All rats were acclimatized for one week before the experiments. The sepsis model induced by small cecal ligation and puncture operation (CLP) was carried out as previously described [22, 23]. In brief, the general anesthesia was induced by i.p. injection of $80 \mathrm{mg} / \mathrm{kg}$ ketamine and $10 \mathrm{mg} / \mathrm{kg}$ xylazine. A $3-\mathrm{cm}$ midline abdominal incision was made. The cecal content was gently pushed toward distal cecum. Small ligation (10\% of distal cecum) was performed with a surgical spool suture. The distal cecum was finally carried out "through-and-through" puncture once with an 18-G needle. The sham-operated individuals underwent the same procedure except for CLP. These rats were sacrificed $24 \mathrm{hr}$ after operation.

Reagents and arrange for experiments to animals

Berberine hydrochloride and ICG001, purchased from MilliporeSigma Corporation, USA, were dissolved in sterile $0.01 \%$ DMSO solution. These animals were randomly allocated into control and 4 experimental groups as follows: sham-operated control group, experimental group I (CLP), II (CLP plus Ber25), III (CLP plus Ber50) and IV (CLP plus Ber50 plus ICG001). There were 10 rats in each group. The rats in group II-IV 


\section{Cellular Physiology Cell Physiol Biochem 2018;49:1342-1351

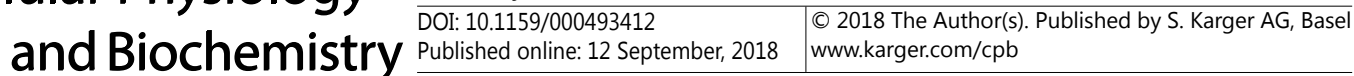

He et al.: Berberine Protects Gut-Vascular Barrier in Sepsis

were gavaged daily with berberine at the dose of 25 (Ber25) or 50 (Ber50) mg/kg for 5 days [24] before CLP operation. ICG001 at a dose of $10 \mathrm{mg} / \mathrm{kg} / \mathrm{d}$ was given by daily i.p. injection for 7 days [25] prior to CLP procedure.

\section{Serum endotoxin level measurement}

The blood samples were drawn from the abdominal aorta prior to the sacrifice and centrifuged at $6000 \mathrm{xg}$ for $5 \mathrm{~min}$ at $4^{\circ} \mathrm{C}$. The concentration of serum endotoxin was assayed by a limulus amebocyte lysate kit (QCL-1000 ${ }^{\mathrm{TM}}$, USA) according to manufactrue's protocol. The results of serum endotoxin level were expressed as $\mathrm{EU} / \mathrm{ml}$.

\section{Jejunal microvascular permeability}

The microvascular permeability was assayed by Evans blue (EB) method as previously described [26]. EB (MW, $980 \mathrm{Da}$ ) binds irreversibly to plasma albumin in a 10:1 molar ratio both in vivo and in vitro. In quantitative studies of vascular permeability, EB is injected into the bloodstream where it rapidly binds to plasma albumin. When the plasma extravasates from vessels, the EB-albumin complex leaks into surrounding tissues [27]. In this experiment, EB was dissolved in $0.9 \%$ saline $(30 \mathrm{mg} / \mathrm{ml})$ and sonicated for $5 \mathrm{~min}$ in an ultrasonic cleaner, and finally filtered via a 5- $\mu \mathrm{m}$ filter (Millipore). EB was injected into the femoral vein of rats. $24 \mathrm{hr}$ later, the rats were perfused transcardially with saline. EB was extracted from the scraped fresh mucosal tissues [28] of distal jejunum by incubation in $5 \mathrm{ml}$ of formamide at $54{ }^{\circ} \mathrm{C}$ for $24 \mathrm{hr}$. EB was quantified by measuring its absorption at a wavelength of $620 \mathrm{~nm}$ by a spectrometer. The results were expressed as $\mu \mathrm{g} \mathrm{EB/g}$ fresh tissue [26].

\section{Cell culture and treatment}

The Escherichia coli lipopolysaccharide (serotype 055:B5) was obtained from MilliporeSigma Corporation, USA, and RIMECs was purchased from Wuhan Biofavor Biotech Corporation, China. The cells were cultured in the complete EBM-2 basal medium supplemented with $10 \%$ fetal bovine serum (FBS) on $0.2 \%$ gelatin-coated plates under a $37^{\circ} \mathrm{C}$ and $5 \% \mathrm{CO}_{2}$ atmosphere. When RIMECs reached confluency, the cells were treated as follows: ( I ) $0.9 \%$ saline, ( II ) $50 \mathrm{ng} / \mathrm{ml}$ LPS, ( III ) $10 \mu \mathrm{M}$ berberine hydrochloride (ber10) plus $50 \mathrm{ng} / \mathrm{ml} \mathrm{LPS,} \mathrm{(} \mathrm{IV} \mathrm{)} 20 \mu \mathrm{M}$ berberine hydrochloride ( ber20 ) plus $50 \mathrm{ng} / \mathrm{ml}$ LPS, and ( V ) ber20 plus $50 \mathrm{ng} / \mathrm{ml}$ LPS plus $10 \mu \mathrm{M}$ ICG001 [29], respectively.

\section{Transendothelial permeability measurement}

Transendothelial permeability to dextran was performed as previously described [30] according to manufacturer's instructions using labeled tracer flux across confluent RIMECs grown on the Transwell inserts with polycarbonate filters (Vascular Permeability Assay Kit, Millipore). In brief, FITC-labeled dextran $(\sim 60 \mathrm{kDa})$ was added to the upper chamber. At indicated time points $(0,2,4,6,8 \mathrm{hr}), 50 \mu \mathrm{l}$ of media were collected from the lower chamber. The amount of FITC-labeled dextran filtrating into the lower chamber was determined by the fluorescence spectrophotometer. The experimental data were expressed as arbitrary fluorescence units.

\section{Transendothelial electrical resistance (TEER)}

$2 \times 10^{5}$ RIMECs were cultured to confluence on a Transwell polyester membrane insert $(0.4 \mu \mathrm{m}$ pore size and $6.5 \mathrm{~mm}$ in diameter) (Corning, USA) on 24-well culture plates and were serum-starved overnight. At indicated time points $(0,2,4,6,8 \mathrm{hr})$, the TEER was measured by using Millicell-ERS (Millipore, Germany) as previously described [31-33]. The TEER were detected and compared as the percent change from corresponding baseline values. Each experiment was repeated three times.

\section{Western blotting analysis}

Following 8-hr treatment, the lysates of RIMECs were prepared for Western blotting. The protein concentration was assayed by bicinchoninic acid assay method. After being separated by SDS-PAGE, the proteins were transferred to a PVDF membrane, which was blocked with $5 \%$ skim milk in Tris- buffered saline containing $0.05 \%$ Tween-20. The membrane was incubated with primary antibodies beta-catenin, claudin-12 and vascular endothelial cadherin (VE-cadherin) antibody overnight at $4{ }^{\circ} \mathrm{C}$ and incubated with secondary antibody for $2 \mathrm{hr}$ at $37^{\circ} \mathrm{C}$. The gel bands were photographed and then quantified with 
the ChemiDoc XRS system (Bio-Rad Laboratories). The band intensity of beta-actin was designated as the internal reference.

\section{Statistical analysis}

Results are expressed as mean \pm standard deviation (SD). After analysis of homogeneity, the data of variance homogeneity or heterogeneity was tested by One-way ANOVA or Welch analysis. The least significant difference (LSD) or Dunnett T3 test was used to determine the difference of means among different groups. $P<0.05$ was considered statistically significant. All statistical analyses were done with the SPSS 16.0 statistical software package (SPSS Inc., Chicago, USA).

\section{Results}

The survival rate of rats in sham and experimental groups

The low-grade polymicrobial sepsis was induced by small cecum ligation and puncture. $24 \mathrm{hr}$ after sham operation, the survival rate of control rats was $100 \% .24 \mathrm{hr}$ after CLP, one died and nine survived in experimental group I (survival rate, $90 \%$ ). No rat died in berberine pretreatment groups, namely, the survival rates were all $100 \%$ in experimental group II, III and IV. There was no statistically significant difference in the survival rate among different experimental and sham groups.

Berberine reduces while ICG001 increases serum endotoxemia levels

The effects of berberine and ICG001 on endotoxin accessing to circulation were assessed. When compared with sham group, the rats in CLP group showed a higher endotoxin level $(1.135 \pm 0.109$ vs. $0.096 \pm 0.033 \mathrm{EU} / \mathrm{ml}, P<0.001)$. Berberine significantly reduced endotoxin concentration. The rats in experimental group II and III had lower endotoxin concentrations $(0.863 \pm 0.108$ and $0.569 \pm 0.087 \mathrm{EU} / \mathrm{ml}$, respectively). Ber50 was more efficient to lower endotoxin level in comparison to Ber25 $(P<0.001)$. Co-treatment with ICG001 and Ber50 resulted in an increased level of endotoxin $(0.909 \pm 0.106 \mathrm{EU} / \mathrm{ml}, P<0.001)$ (Fig. 1).

Berberine inhibits while
ICG001 enhances CLP-induced
microvascular permeability
The amount of extravascular EB in mucosa was low $(61.47 \pm 10.73$ $\mu \mathrm{g} / \mathrm{g}$ tissue) in sham group, but significantly elevated in CLP rats $(212.02 \pm 22.45 \mu \mathrm{g} / \mathrm{g}$ tissue $)(P<$ 0.001 ). Berberine markedly reduced CLP-increased vascular permeability. The amount of EB extravasation was $167.62 \pm 12.04$ and $126.76 \pm 14.79$ $\mu \mathrm{g} / \mathrm{g}$ tissue in experimental group II and III, respectively. Statistically, Ber50 was more efficient to reduce EB filtration in comparison to Ber25 $(P<$ 0.001). In group IV, ICG001 abrogated the effect of Ber50 resulting in a raised EB filtration $(171.75 \pm 17.90 \mu \mathrm{g} / \mathrm{g}$ tissue, $P<0.001$ ) (Fig. 2).

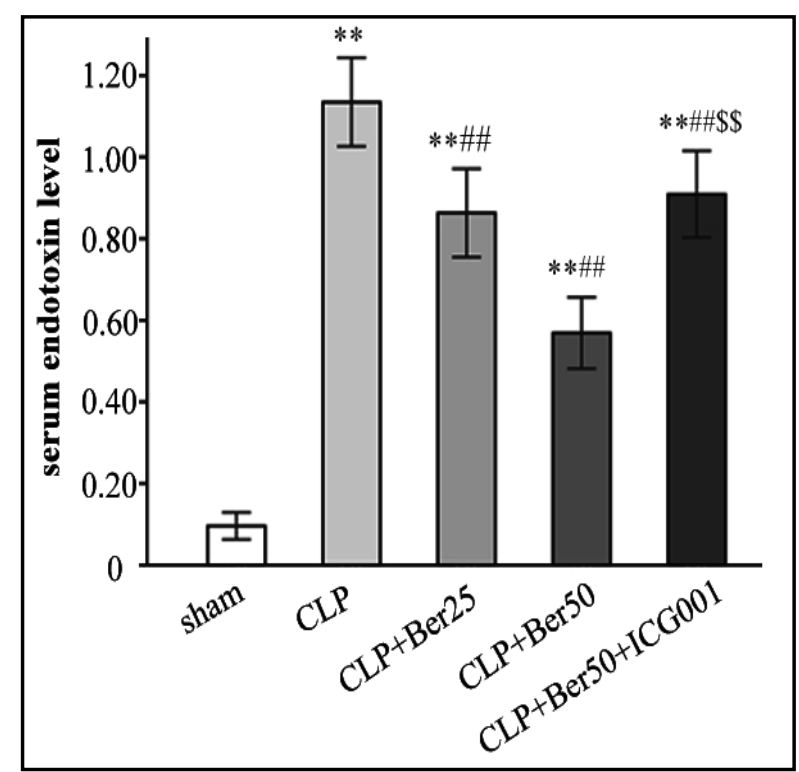

Fig. 1. The serum endotoxin concentration of rats allocated into sham, CLP, CLP plus Ber25, LPS plus Ber50, and CLP plus Ber50 plus ICG001 groups, respectively. ${ }^{*} \mathrm{P}<0.05$, ${ }^{* *} \mathrm{P}<0.01$ vs. sham group; ${ }^{\#} \mathrm{P}<0.05,{ }^{\# \#} \mathrm{P}<0.01$ vs. CLP group; ${ }^{\$} \mathrm{P}<0.05,{ }^{\$} \mathrm{P}<0.01$ vs. CLP plus Ber50 group. 
In vitro berberine inhibits while ICG001 enhances LPSinduced RIMECs permeability As demonstrated in Fig. 3, LPS exposure markedly increased vascular permeability to FITClabeled dextran with time. By contrast, berberine reduced LPSinduced FITC-labeled dextran filtration. Moreover, ber20 was more efficient to reduce dextran filtration when compared with ber10 $(P<0.001)$. ICG001 dampened the effect of ber20, leading to an elevated vascular permeability to dextran.

In vitro berberine increases while ICG001 decreases TEER

The TEER was measured to evaluate endothelial barrier integrity (Table 1). After comparison as percent change from baselines (Fig. 4), TEER did not present significant changes in control group at various time points. Inversely, LPS markedly decreased TEER in a time-dependent manner. Contrarily, berberine attenuated LPS-decreased TEER. Furthermore, ber20 appeared to be more effective to up- regulate TEER in comparison to ber10. However, the upregulatory effect of berberine on TEER was effectively abolished by ICG001 (Fig. 4).

In vitro berberine increases while ICG001 reduces betacatenin, claudin-12 and VEcadherin

As shown in Fig. 5, LPS significantly reduced the generation of beta-catenin (39.97\%), claudin-12 (47.95\%) and VE-cadherin $(51.74 \%)$ compared with the control group. Treatment with ber10 raised LPS-decreased beta-catenin, claudin-12 and VE-cadherin by $14.60 \%, 37.32 \%$ and $30.35 \%$, respectively. Treatment with ber20 increased them by $27.40 \%, 78.42 \%$ and $78.61 \%$, respectively. ICG001 abrogated the effect of ber20 causing a reduction of them by $33.91 \%$, $22.55 \%$ and $34.90 \%$, respectively.

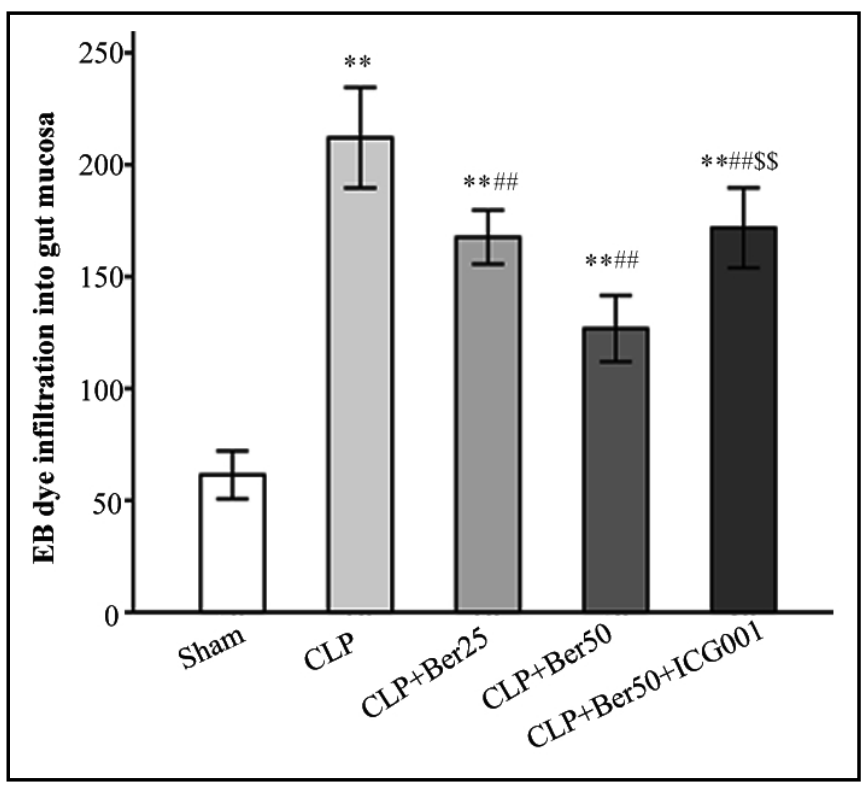

Fig. 2. The amount of EB filtration into jejunal mucosa in rats allocated into sham, CLP, CLP plus Ber25, LPS plus Ber50, and CLP plus Ber50 plus ICG001 groups, respectively. ${ }^{*} \mathrm{P}<0.05,{ }^{* *} \mathrm{P}<0.01$ vs. sham group; ${ }^{\#} \mathrm{P}<0.05,{ }^{\# \#} \mathrm{P}<0.01$ vs. CLP group; ${ }^{\$} \mathrm{P}<0.05,{ }^{\$} \mathrm{P}<0.01$ vs. CLP plus Ber50 group.

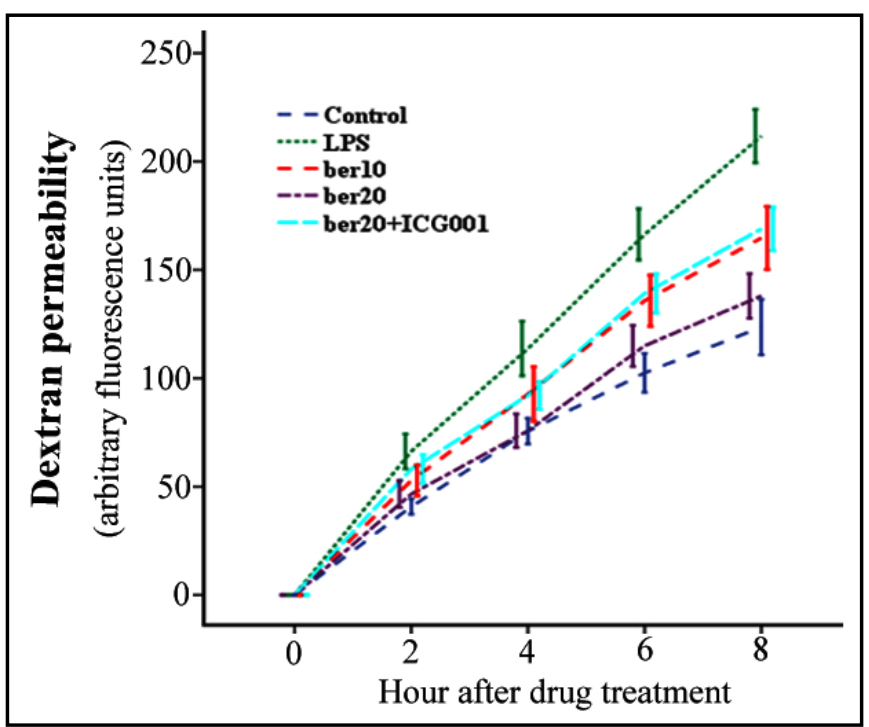

Fig. 3. The transendothelial permeability of RIMECs treated with saline (control), LPS, LPS plus ber10, LPS plus ber20, and LPS plus ber20 plus ICG001, respectively. 
Table 1. In Vitro the measurement of TEER of RIMECs

\begin{tabular}{lccccc}
\hline \multirow{2}{*}{ Group } & \multicolumn{5}{c}{ TEER $\left(\Omega \cdot \mathrm{cm}^{2}\right)$} \\
& $0 \mathrm{hr}$ & $2 \mathrm{hr}$ & $4 \mathrm{hr}$ & $6 \mathrm{hr}$ & $8 \mathrm{hr}$ \\
\hline control & $51.57 \pm 2.91$ & $51.49 \pm 3.80$ & $51.51 \pm 3.68$ & $51.58 \pm 3.47$ & $51.46 \pm 3.59$ \\
LPS & $51.56 \pm 3.65$ & $45.98 \pm 2.89$ & $41.11 \pm 4.04$ & $36.76 \pm 4.23$ & $32.43 \pm 4.06$ \\
LPS+ber10 & $51.50 \pm 3.12$ & $47.88 \pm 3.00$ & $44.08 \pm 4.53$ & $41.09 \pm 4.73$ & $38.03 \pm 3.22$ \\
LPS+ber20 & $51.53 \pm 3.25$ & $48.52 \pm 3.84$ & $46.04 \pm 4.16$ & $43.74 \pm 4.98$ & $42.09 \pm 4.11$ \\
LPS+ber20+ICG001 & $51.52 \pm 3.89$ & $47.16 \pm 4.12$ & $44.26 \pm 3.41$ & $41.04 \pm 3.95$ & $37.76 \pm 3.81$ \\
\hline
\end{tabular}

Fig. 4. The transendothelial electrical resistance of RIMECs treated with saline (control), LPS, LPS plus ber10, and LPS plus ber20, and LPS plus ber20 plus ICG001, respectively.
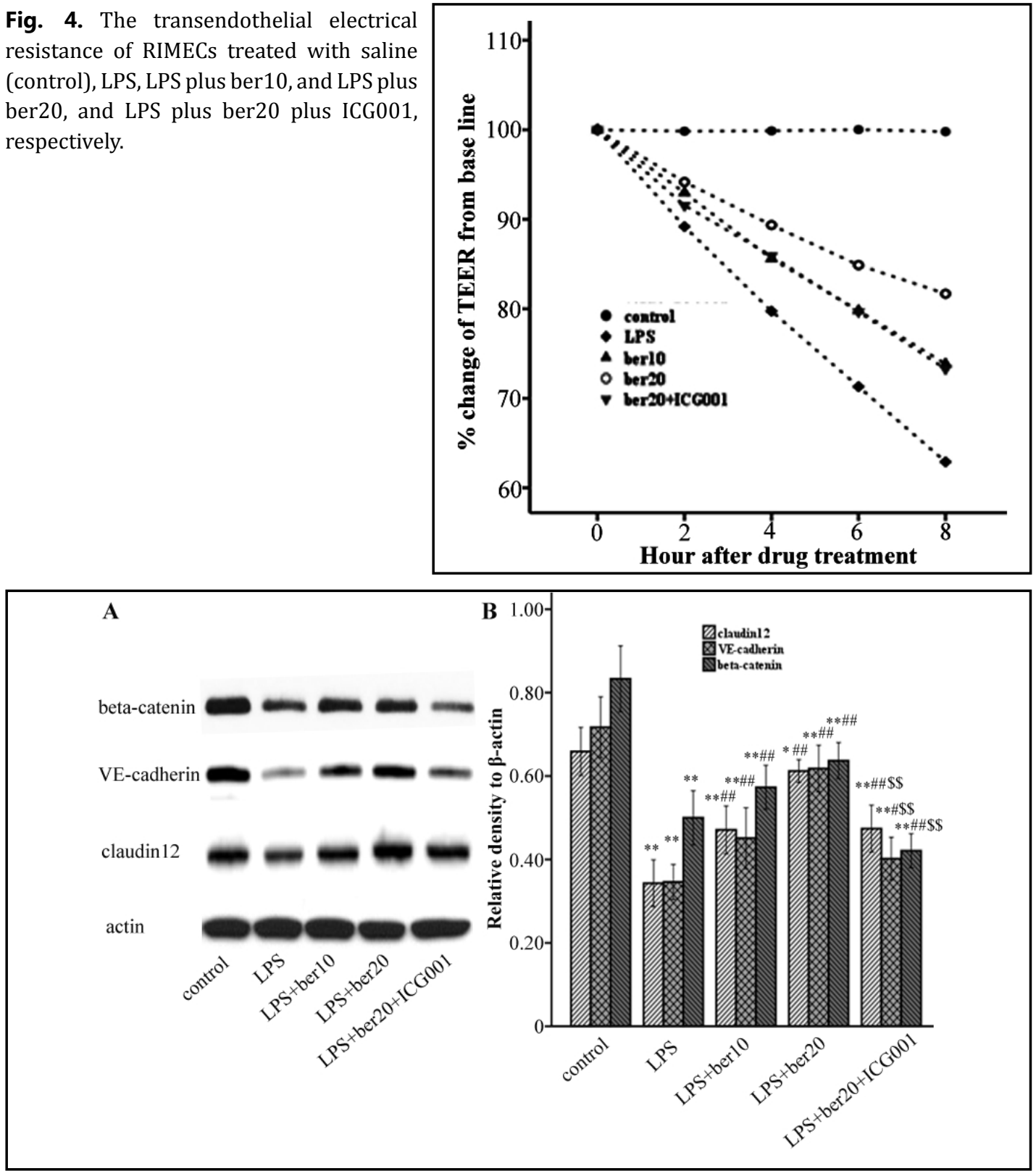

Fig. 5. The expression of claudin-12, VE-cadherin and beta-catenin in RIMECs treated with saline (control), LPS, LPS plus ber10, LPS plus ber20, and LPS plus ber20 plus ICG001, respectively. A: The representative gels for claudin-12, VE-cadherin and beta-catenin protein. B: The relative density of claudin-12, VE-cadherin and beta-catenin was calculated relative to that of beta-actin. ${ }^{*} \mathrm{P}<0.05,{ }^{* *} \mathrm{P}<0.01$ vs. control group; ${ }^{\#} \mathrm{P}<0.05$,

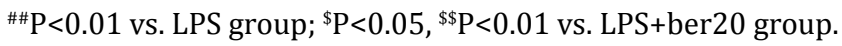




\section{Cellular Physiology Cell Physiol Biochem 2018;49:1342-1351

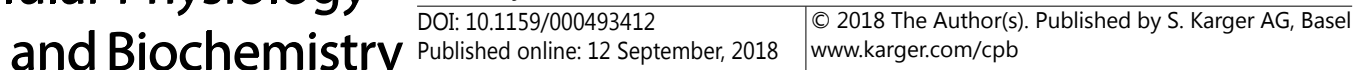 \\ He et al.: Berberine Protects Gut-Vascular Barrier in Sepsis}

\section{Discussion}

The intestinal mucosa is rich in fenestrated capillaries allowing the passage of large biomolecules. Recently, Spadoni et al. have confirmed the existence of GVB with the morphological and functional characteristics resembling to the blood brain barrier in murine and human intestines that plays a key role in avoiding indiscriminate trafficking of bacteria from the gut into bloodstream, and the vascular barrier integrity can be altered by Salmonella typhimurium via the modulation of the Wnt/beta-catenin pathway [34]. Thus, the alteration of gut capillary influences GVB [2]. The murine CLP procedure is a classical model of sepsis, which may adversely influence GVB. In the experimental study performed by Rittirsch [23], the rats possess positive blood cultures containing mixed enteric microorganisms which are detectable as early as $6 \mathrm{hr}$ following CLP. These rats begin to show clinical signs of sepsis at $12 \mathrm{hr}$ after CLP and lethality usually begins at 18 24 hr after CLP. $24 \mathrm{hr}$ following CLP, the survival rate is $90 \%, 65 \%$ and $40 \%$ in low-, mid- and high-grade rats, respectively [23]. In our low-grade sepsis model, the survival rate of rats was $90 \% 24 \mathrm{hr}$ after CLP operation. Conversely, the survival rate of rats in berberine groups (II-III) reached to $100 \%$. It is known that Wnt/beta-catenin signaling plays a positive role in the maintenance of GVB integrity [2]. Thus, ICG001 was employed to repress Wnt/beta-catenin signaling. However, ICG001 (group IV) did not increase the mortality of berberine-treated rats. Thus, berberine exerted a protective role for survival in CLP-induced sepsis.

Spadoni et al. have demonstrated that Salmonella typhimurium is capable of inhibiting the activation of Wnt/beta-catenin pathway [2,34]. This signaling has been reported elsewhere to exert the anti-inflammatory or pro-inflammatory properties [35-39]. Indeed, in the intestine the activation of Wnt/beta-catenin pathway helps to maintain GVB function $[2,34]$. Given that berberine is capable of ameliorating impaired gut mucosal barrier [28, 40-43], in this study we investigated if berberine might maintain GVB function though the modulation of the Wnt/beta-catenin pathway. The experimental findings revealed serum endotoxin level was very low in sham-operated rats but significantly elevated in CLP matches, indicating the possibility that sepsis disturbed GVB function, thereby resulting in substantial entrance of bacteria and toxins into the bloodstream through capillaries which are located beneath the intestinal epithelium [2]. Expectedly, berberine lowered the endotoxin concentration in a dose-dependent manner, indicative of a protective role of it in alleviating endotoxemia. Nevertheless, administration of ICG001 to berberine-treated rats gave rise to the deterioration of sepsis, indicating that Wnt/beta-catenin signaling pathway was possibly activated by berberine.

The amount of extravascular EB within gut mucosa was detected to assess the effect of berberine on GVB permeability. The data revealed that the amount of EB was much more in CLP rats than that in sham-operated individuals. Berberine significantly reduced CLPinduced EB extravasation. Similarly, in vitro LPS exposure rapidly increased the permeability of RIMECs to FITC-dextran, and this effect of LPS was antagonized by berberine. ICG001 damaged berberine's improving vascular permeability in vivo and vitro. Given that a decrease in TEER value is also a sensitive index to hint vascular barrier dysfunction, we assayed the TEER in RIMECs. High pharmacologic concentrations of LPS $(1 \sim 50 \mu \mathrm{g} / \mathrm{ml})$ often cause numerous cell death and apoptosis [44], we chose a low pathological concentration of LPS $(50 \mathrm{ng} / \mathrm{ml})$ instead of physiological concentrations $(0 \sim 10 \mathrm{ng} / \mathrm{ml})$ [44]. Our data showed TEER significantly decreased in RIMECs challenged with LPS only, but markedly increased in those cells co-treated with LPS and berberine. Nevertheless, the upregulation of TEER by berberine was abolished by ICG001. Thus, our in vivo and vitro studies confirmed that berberine maintained GVB function via the activation of the Wnt/beta-catenin signaling pathway in sepsis.

In the intestinal endothelial cells, VE-cadherin and beta-catenin are the main components of $\mathrm{AJ}$ molecules, and claudin- 12 is the main TJ molecule. Both TJ and AJ proteins are responsible for the vascular endothelial barrier function [2]. In this experiment, we detected the protein expression of claudin-12, VE-cadherin and beta-catenin in RIMECs. 
Expectedly, the RIMECs exposed to LPS stimulus expressed lesser claudin-12, VE-cadherin and beta-catenin than those cells treated by saline. Co-treatment with LPS and berberine abrogated the detrimental effects of LPS. Nevertheless, the upregulation of TJ/AJ production by berberine was curbed by ICG001, suggesting that the activation of Wnt/beta-catenin signaling pathway by berberine was involved in the maintenance of GVB function.

\section{Conclusion}

This study focused on the regulatory effect of berberine on endotoxin level, vascular permeability, TEER and TJ/AJ expression in vivo and in vitro. The findings suggested that in this rat polymicrobial sepsis model berberine significantly alleviated endotoxemia, decreased vascular permeability, raised TEER and increased TJ/AJ protein production. Importantly, our experiments confirmed that berberine protected GVB function via the modulation of the Wnt/beta-catenin signaling pathway in sepsis.

\section{Acknowledgements}

We thank Associate Professor Ti Zhang, who is the director of Department of Gastrointestinal Surgery, for his revising the manuscript critically for important intellectual content.

\section{Disclosure Statement}

The authors declare that no conflict of interest exists.

\section{References}

1 Nolan JP, Hare DK, McDevitt JJ, Ali MV: In vitro studies of intestinal endotoxin absorption. I. Kinetics of absorption in the isolated everted gut sac. Gastroenterology 1977;72:434-439.

2 Spadoni I, Pietrelli A, Pesole G, Rescigno M: Gene expression profile of endothelial cells during perturbation of the gut vascular barrier. Gut Microbes 2016;7:540-548.

3 Mathan VI, Penny GR, Mathan MM, Rowley D: Bacterial lipopolysaccharide-induced intestinal microvascular lesions leading to acute diarrhea. J Clin Invest 1988;82:1714-1721.

4 Hutcheson IR, Whittle BJ, Boughton-Smith NK: Role of nitric oxide in maintaining vascular integrity in endotoxin-induced acute intestinal damage in the rat. Br J Pharmacol 1990;101:815-820.

5 Boughton-Smith NK, Evans SM, Laszlo F, Whittle BJ, Moncada S: The induction of nitric oxide synthase and intestinal vascular permeability by endotoxin in the rat. Br J Pharmacol 1993;110:1189-1195.

-6 Garcia Soriano F, Liaudet L, Marton A, Hasko G, Batista Lorigados C, Deitch EA, Szabo C: Inosine improves gut permeability and vascular reactivity in endotoxic shock. Crit Care Med 2001;29:703-708.

7 Peng JH, Cui T, Huang F, Chen L, Zhao Y, Xu L, Xu LL, Feng Q, Hu YY: Puerarin ameliorates experimental alcoholic liver injury by inhibition of endotoxin gut leakage, Kupffer cell activation, and endotoxin receptors expression. J Pharmacol Exp Ther 2013;344:646-654.

-8 Ciccia F, Guggino G, Rizzo A, Alessandro R, Luchetti MM, Milling S, Saieva L, Cypers H, Stampone T, Di Benedetto P, Gabrielli A, Fasano A, Elewaut D, Triolo G: Dysbiosis and zonulin upregulation alter gut epithelial and vascular barriers in patients with ankylosing spondylitis. Ann Rheum Dis 2017;76:11231132.

-9 Zhang HQ Wang HD, Lu DX, Qi RB, Wang YP, Yan YX, Fu YM: Berberine inhibits cytosolic phospholipase A2 and protects against LPS-induced lung injury and lethality independent of the alpha2-adrenergic receptor in mice. Shock 2008;29:617-622. 


\section{Cellular Physiology Cell Physiol Biochem 2018;49:1342-1351 \begin{tabular}{l|l|l} 
and Biochemistry & DOI: 10.1159/000493412 & $\begin{array}{l}\text { C } 2018 \text { The Author(s). Published by S. Karger AG, Basel } \\
\text { www.karger.com/cpb }\end{array}$
\end{tabular}

He et al.: Berberine Protects Gut-Vascular Barrier in Sepsis

10 Wu YH, Chuang SY, Hong WC, Lai YJ, Chang GJ, Pang JH: Berberine reduces leukocyte adhesion to LPSstimulated endothelial cells and VCAM-1 expression both in vivo and in vitro. Int J Immunopathol Pharmacol 2012;25:741-750.

11 Wang C, Li J, Lv X, Zhang M, Song Y, Chen L, Liu Y: Ameliorative effect of berberine on endothelial dysfunction in diabetic rats induced by high-fat diet and streptozotocin. Eur J Pharmacol 2009;620:131137.

-12 Hu Y, Chen X, Duan H, Mu X: Pulsatilla decoction and its active ingredients inhibit secretion of NO, ET-1, TNF-alpha, and IL-1 alpha in LPS-induced rat intestinal microvascular endothelial cells. Cell Biochem Funct 2009;27:284-288.

$13 \mathrm{Hu}$ Y, Chen X, Duan H, Mu X: Chinese herbal medicinal ingredients inhibit secretion of IL-6, IL-8, E-selectin and TXB2 in LPS-induced rat intestinal microvascular endothelial cells. Immunopharmacol Immunotoxicol 2009;31:550-555.

14 Tian P, Ge H, Liu H, Kern TS, Du L, Guan L, Su S, Liu P: Leukocytes from diabetic patients kill retinal endothelial cells: effects of berberine. Mol Vis 2013;19:2092-2105.

15 Li H, He C, Wang J, Li X, Yang Z, Sun X, Fang L, Liu N: Berberine activates peroxisome proliferator-activated receptor gamma to increase atherosclerotic plaque stability in Apoe(-/-) mice with hyperhomocysteinemia. J Diabetes Investig 2016;7:824-832.

16 Cheng F, Wang Y, Li J, Su C, Wu F, Xia WH, Yang Z, Yu BB, Qiu YX, Tao J: Berberine improves endothelial function by reducing endothelial microparticles-mediated oxidative stress in humans. Int J Cardiol 2013;167:936-942.

17 Zhang X, Wang C, Li Y, Dong L, Cui L, Wang L, Liu Z, Qiao H, Zhu C, Xing Y, Cao X, Ji Y, Zhao K: Neuroprotection of early and short-time applying berberine in the acute phase of cerebral ischemia: upregulated pAkt, pGSK and pCREB, down-regulated NF-kappaB expression, ameliorated BBB permeability. Brain Res 2012;1459:61-70.

18 Carotenuto P, Fassan M, Pandolfo R, Lampis A, Vicentini C, Cascione L, Paulus-Hock V, Boulter L, Guest R, Quagliata L, Hahne JC, Ridgway R, Jamieson T, Athineos D, Veronese A, Visone R, Murgia C, Ferrari G, Guzzardo V, et al.: Wnt signalling modulates transcribed-ultraconserved regions in hepatobiliary cancers. Gut 2017;66:1268-1277.

19 Jiao X, Cai J, Yu X, Ding X: Paracrine Activation of the Wnt/beta-Catenin Pathway by Bone Marrow Stem Cell Attenuates Cisplatin-Induced Kidney Injury. Cell Physiol Biochem 2017;44:1980-1994.

20 Taiyab A, Korol A, Deschamps PA, West-Mays JA: beta-Catenin/CBP-Dependent Signaling Regulates TGFbeta-Induced Epithelial to Mesenchymal Transition of Lens Epithelial Cells. Invest Ophthalmol Vis Sci 2016;57:5736-5747.

21 Sasaki T, Hwang H, Nguyen C, Kloner RA, Kahn M: The small molecule Wnt signaling modulator ICG-001 improves contractile function in chronically infarcted rat myocardium. PLoS One 2013;8:e75010.

-22 Zhang HX, Du JM, Ding ZN, Zhu XY, Jiang L, Liu YJ: Hydrogen sulfide prevents diaphragm weakness in cecal ligation puncture-induced sepsis by preservation of mitochondrial function. Am J Transl Res 2017;9:32703281.

23 Rittirsch D, Huber-Lang MS, Flierl MA, Ward PA: Immunodesign of experimental sepsis by cecal ligation and puncture. Nat Protoc 2009;4:31-36.

-24 Li F, Wang HD, Lu DX, Wang YP, Qi RB, Fu YM, Li CJ: Neutral sulfate berberine modulates cytokine secretion and increases survival in endotoxemic mice. Acta Pharmacol Sin 2006;27:1199-1205.

25 Alapati D, Rong M, Chen S, Hehre D, Hummler SC, Wu S: Inhibition of beta-catenin signaling improves alveolarization and reduces pulmonary hypertension in experimental bronchopulmonary dysplasia. Am J Respir Cell Mol Biol 2014;51:104-113.

-26 Chen YM, Zhang JS, Duan XL: Changes of microvascular architecture, ultrastructure and permeability of rat jejunal villi at different ages. World J Gastroenterol 2003;9:795-799.

-27 Xu Q, Qaum T, Adamis AP: Sensitive blood-retinal barrier breakdown quantitation using Evans blue. Invest Ophthalmol Vis Sci 2001;42:789-794.

28 He Y, Yuan X, Zhou G, Feng A: Activation of IGF-1/IGFBP-3 signaling by berberine improves intestinal mucosal barrier of rats with acute endotoxemia. Fitoterapia 2018;124:200-205.

29 Teo JL, Ma H, Nguyen C, Lam C, Kahn M: Specific inhibition of CBP/beta-catenin interaction rescues defects in neuronal differentiation caused by a presenilin-1 mutation. Proc Natl Acad Sci U S A 2005;102:1217112176. 


\section{Cellular Physiology Cell Physiol Biochem 2018;49:1342-1351 \begin{tabular}{l|l} 
DOI: 10.1159/000493412 & $\begin{array}{l}\text { O 2018 The Author(s). Published by S. Karger AG, Basel } \\
\text { www.karger.com/cpb }\end{array}$
\end{tabular}}

He et al.: Berberine Protects Gut-Vascular Barrier in Sepsis

30 Dudek SM, Munoz NM, Desai A, Osan CM, Meliton AY, Leff AR: Group V phospholipase A2 mediates barrier disruption of human pulmonary endothelial cells caused by LPS in vitro. Am J Respir Cell Mol Biol 2011;44:361-368.

-31 Fujimoto T, Inoue T, Maki K, Inoue-Mochita M, Tanihara H: Vascular Endothelial Growth Factor-A Increases the Aqueous Humor Outflow Facility. PLoS One 2016;11:e0161332.

-32 Magalhaes A, Matias I, Palmela I, Brito MA, Dias S: LDL-Cholesterol Increases the Transcytosis of Molecules through Endothelial Monolayers. PLoS One 2016;11:e0163988.

-33 Fujimoto T, Inoue T, Kameda T, Kasaoka N, Inoue-Mochita M, Tsuboi N, Tanihara H: Involvement of RhoA/ Rho-associated kinase signal transduction pathway in dexamethasone-induced alterations in aqueous outflow. Invest Ophthalmol Vis Sci 2012;53:7097-7108.

-34 Spadoni I, Zagato E, Bertocchi A, Paolinelli R, Hot E, Di Sabatino A, Caprioli F, Bottiglieri L, Oldani A, Viale G, Penna G, Dejana E, Rescigno M: A gut-vascular barrier controls the systemic dissemination of bacteria. Science 2015;350:830-834.

35 Ma B, Hottiger MO: Crosstalk between Wnt/beta-Catenin and NF-kappaB Signaling Pathway during Inflammation. Front Immunol 2016;7:378.

-36 Gatica-Andrades M, Vagenas D, Kling J, Nguyen TTK, Benham H, Thomas R, Korner H, Venkatesh B, Cohen J, Blumenthal A: WNT ligands contribute to the immune response during septic shock and amplify endotoxemia-driven inflammation in mice. Blood Adv 2017;1:1274-1286.

-37 Guo C, Yang RJ, Jang K, Zhou XL, Liu YZ: Protective Effects of Pretreatment with Quercetin Against Lipopolysaccharide-Induced Apoptosis and the Inhibition of Osteoblast Differentiation via the MAPK and Wnt/beta-Catenin Pathways in MC3T3-E1 Cells. Cell Physiol Biochem 2017;43:1547-1561.

-38 El-Sayyad SM, Soubh AA, Awad AS, El-Abhar HS: Mangiferin protects against intestinal ischemia/ reperfusion-induced liver injury: Involvement of PPAR-gamma, GSK-3beta and Wnt/beta-catenin pathway. Eur J Pharmacol 2017;809:80-86.

39 Libro R, Giacoppo S, Bramanti P, Mazzon E: Is the Wnt/beta-catenin pathway involved in the antiinflammatory activity of glucocorticoids in spinal cord injury? Neuroreport 2016;27:1086-1094.

40 Feng AW, Yu C, Mao Q Li N, Li QR, Li JS: Berberine hydrochloride attenuates cyclooxygenase-2 expression in rat small intestinal mucosa during acute endotoxemia. Fitoterapia 2011;82:976-982.

41 Feng AW, Gao W, Zhou GR, Yu R, Li N, Huang XL, Li QR, Li JS: Berberine ameliorates COX-2 expression in rat small intestinal mucosa partially through PPARgamma pathway during acute endotoxemia. Int Immunopharmacol 2012;12:182-188.

42 Gu L, Li N, Gong J, Li Q, Zhu W, Li J: Berberine ameliorates intestinal epithelial tight-junction damage and down-regulates myosin light chain kinase pathways in a mouse model of endotoxinemia. J Infect Dis 2011;203:1602-1612.

43 Niu L, Qiao W, Hu Z, Li N, Huang Q, Gong J, Li Q Zhu W, Li J: Berberine attenuates lipopolysaccharideinduced impairments of intestinal glutamine transport and glutaminase activity in rat. Fitoterapia 2011;82:323-330.

44 Guo S, Nighot M, Al-Sadi R, Alhmoud T, Nighot P, Ma TY: Lipopolysaccharide Regulation of Intestinal Tight Junction Permeability Is Mediated by TLR4 Signal Transduction Pathway Activation of FAK and MyD88. J Immunol 2015;195:4999-5010. 